\title{
Factors associated with Allergic Rhinitis in Colombian subpopulations aged 1 to 17 and 18 to 59*
}

\author{
Augusto Peñaranda', Elizabeth Garcia², Ana M. Barragán ${ }^{3,4}$, Martín A. Rondón ${ }^{5}$, \\ Adriana Pérez ${ }^{6,7}$, María X. Rojas ${ }^{5}$, Luis Caraballo8, Rodolfo J. Dennis ${ }^{3,5}$ \\ ' Division of Otorhinolaryngology, Fundación Santa Fe de Bogotá, Bogotá, Colombia \\ 2Division of Paediatric Allergies, Fundación Santa Fe de Bogotá, Bogotá, Colombia \\ ${ }^{3}$ Research Department, Fundación Cardioinfantil - Instituto de Cardiología, Bogotá, Colombia \\ ${ }^{4}$ Escuela de Medicina y Ciencias de la Salud, Universidad del Rosario, Bogotá, Colombia \\ ${ }^{5}$ Department of Clinical Epidemiology and Biostatistics, School of Medicine, Pontificia Universidad Javeriana, Bogotá, Colombia \\ ${ }^{6}$ Division of Biostatistics, School of Public Health, The University of Texas Health Science Center at Houston, Austin, TX, United States \\ Michael \& Susan Dell Centre for Healthy Living, The University of Texas Health Science Center at Houston, Austin, TX, United States \\ ${ }^{8}$ Institute for Immunological Research, University of Cartagena, Cartagena, Colombia
}

Rhinology 54: 0-0, 2016

DOI:10.4193/Rhino 14.234

*Received for publication:

September 23, 2014

Accepted: August 20, 2015

\begin{abstract}
Background: Several studies have shown variations in the prevalence of allergic rhinitis (AR) around the world, and different potential predisposing factors. More studies are needed on risk factors, specifically in developing countries. This study explored the association of several factors and AR among urban residents in six cities of Colombia.

Methodology: A cross-sectional study and a nested case-control study were carried out between 2009 and 2010 involving two Colombian subpopulations: children/adolescents and adults. Cases were affirmative respondents to "In the past 12 months, have you (or your child) had a problem with sneezing or a running or blocked nose, when you (or your child) did not have a cold or the flu?" "Controls" were subjects who never had been diagnosed with asthma, AR or atopic eczema by a physician, and whom did not report any symptoms in the past twelve months. Weighted logistic regression was used to assess the association of different factors with case/control status.
\end{abstract}

Results: Factors associated with AR in children/adolescents were family history of AR, acetaminophen consumption and high socioeconomic status. Among adults, family history of asthma, AR and atopic eczema, and cetaminophen consumption were associated with AR. Consumption of cereals among children/adolescents and eating eggs among adults showed protective associations.

Conclusions: Our findings suggest the presence of previously unknown cultural, environmental and family factors associated with the presence of AR in Colombia.

Key words: rhinitis, chronic diseases, odds ratio, Colombia, case-control studies

\section{Introduction}

Allergic Rhinitis is the nasal mucosae reaction to allergens in the form of an exaggerated inflammation. AR is a chronic disease that affects a significant proportion of the world population (1). Four hundred million people worldwide suffer from AR, with peak prevalence among adolescents ${ }^{(1)}$. Interaction between genetics, lifestyle and environment characterizes this complex disease and makes it hard to control ${ }^{(2)}$. AR often coexists with other diseases like asthma, rhino-sinusitis and allergic conjunctivitis, among others ${ }^{(2)}$. The association with asthma merits special attention due to an increased risk of developing an asthmatic crisis in patients with non-controlled $A R^{(2)}$. Symptoms associated with AR are under-reported by patients and health personnel ${ }^{(2)}$. Only one out of three affected indivi- 
duals in the USA sought medical care in a 1998 report ${ }^{(3)}$, while others sought medical care just in severe cases ${ }^{(2)}$. Even after seeking health care, patients are often left with unmet needs due to inadequate treatment ${ }^{(4)}$. The impact of AR in populations can be measured by the economic loss due to absenteeism from work and school, as well as low performance in daily activities of adults and children ${ }^{(5)}$. Additionally, AR decreases quality of life, because respiratory symptoms are the main factors related with low quality of life ${ }^{(6,7)}$.

Prevalence studies worldwide have focussed separately on children or adults. The 2008 International Study of Asthma and Allergy in Childhood phase three (ISAAC III), reported the prevalence of AR among children aged 6-7 years worldwide to be between $7.4 \%$ and $43.4 \%$ (median $19.7 \%$ ) for the last 12 months period, and among those aged $13-14$ years, between $10.4 \%$ and $80.6 \%$ (median 32.3\%) (1). Studies carried out in American adult populations revealed a prevalence of rhinitis between $10.0 \%$ and $30.0 \%{ }^{(7)}$, while in Europe prevalence is reported between $11.8 \%$ and $46.0 \%{ }^{(8,9)}$. The 2010 Allergies in the Latin America Survey, showed prevalence ranging from $3.5 \%$ to $11.4 \%$ of "AR or nasal allergy" diagnosed by a physician in general populations ${ }^{(5)}$. In spite of the apparent low prevalence in the region, the evidence shows a marked increase in past years ${ }^{(1,8)}$.

Studies carried out in Colombia showed higher prevalence than those reported for the Latin American region and showed an increase using the same ISAAC definition of AR. In 2012, a study carried out in Bogotá, the capital of Colombia, showed the prevalence of $A R$ symptoms for the last 12 months period among adolescents to be near $37 \%$, and among school children near $31 \%{ }^{(9)}$. Previously in 1998-2000, the prevalence of AR among the urban population aged 1 to 59 years in six Colombians cities showed a prevalence of $22.6 \%(95 \% \mathrm{Cl}, 21.6-23.6){ }^{(10)}$. In 2009-2010, the prevalence of AR among the urban population aged 1 to 59 years form the same Colombian cities, showed a prevalence of AR of $31.7 \%(95 \% \mathrm{Cl}, 29.5-33.9)^{(11)}$. The distribution of AR prevalence by age group showed a higher percentage in the 5 to 17 years age group, followed by those 1 to 4 years and adults from 18 to 59 years of age $(46.9 \%, 30.4 \%$ and $26.3 \%$ respectively) ${ }^{(11)}$.

Based on these previous studies, the purpose of this study was to identify environmental and demographic characteristics and other possible factors associated with AR in six major cities of Colombia. This information represents the first step toward making health personnel, policy makers and individuals aware of the magnitude and distribution of AR in Colombia, and provides evidence of possible related factors to target future interventions seeking to reduce the burden of this disease.

\section{Materials and methods}

\section{Study design}

An observational cross-sectional survey was carried out in six Colombian cities (Bogotá, Bucaramanga, Cali, Cartagena, Medellín and San Andrés). In addition, a nested case-control study design was designed to assess associated factors. A detailed description of this survey and the methodology has been published (11) and a summary is provided here. Individuals aged 1-59 years were surveyed between 2009 and 2010. People confined to hospitals or institutions for the chronically ill patients, those living in institutions for the disabled, or with an altered mental state, dementia, or mental disability, were excluded from the study. We used a school-based stratified design to identify subjects 5-17 years old, and carried out a community-based strategy to identify subjects 1-4 years old and 18-59 years old. Sampling weights were developed to account for the complex design. A total of 5978 subjects were proportionally weighted to represent the actual population size in all six cities. Due to the definitions of case and control that we used for the nested case-control study, 5008 subjects were included in this study. The protocol was approved by the Clinical Research Ethics Committee at Fundación Cardioinfantil-Instituto de Cardiología in Bogotá, Colombia (IORG0006438).

\section{Questionnaire and data collection}

The questionnaire used questions developed and validated by The International Study of Asthma and Allergy in Childhood (ISAAC) ${ }^{(12)}$. The following items were added from the current Spanish environmental questionnaire of the ISAAC III study ${ }^{(13)}$ : frequency of eating or drinking selected foods, frequency of exercising, combustible material for cooking, socio-economic status, frequency of acetaminophen consumption, mother's educational attainment and frequency of public transportation passing through the street where subjects lived.

Answers from the cross-sectional survey were used to define cases and controls. A "case" was defined as a subject who reported current symptoms of AR by responding "yes" to the following question: "In the past 12 months, have you (or your child) had a problem with sneezing or a running or blocked nose, when you (or your child) did not have a cold or the flu?". "Controls" were subjects who never had been diagnosed with asthma, allergic rhinitis or atopic eczema by a physician, and answered "no" to the following questions:

1. "In the past 12 months, have you (or your child) had a problem with sneezing or a running or blocked nose, when you (or your child) did not have a cold or the flu?"

2. "Have you (or your child) had wheezing or whistling in the chest in the past 12 months?"

3. "Have you (or your child) had an itchy rash at any time in the past 12 months in specific body areas?" 
Table 1. Variables explored in children/adolescents and adults.

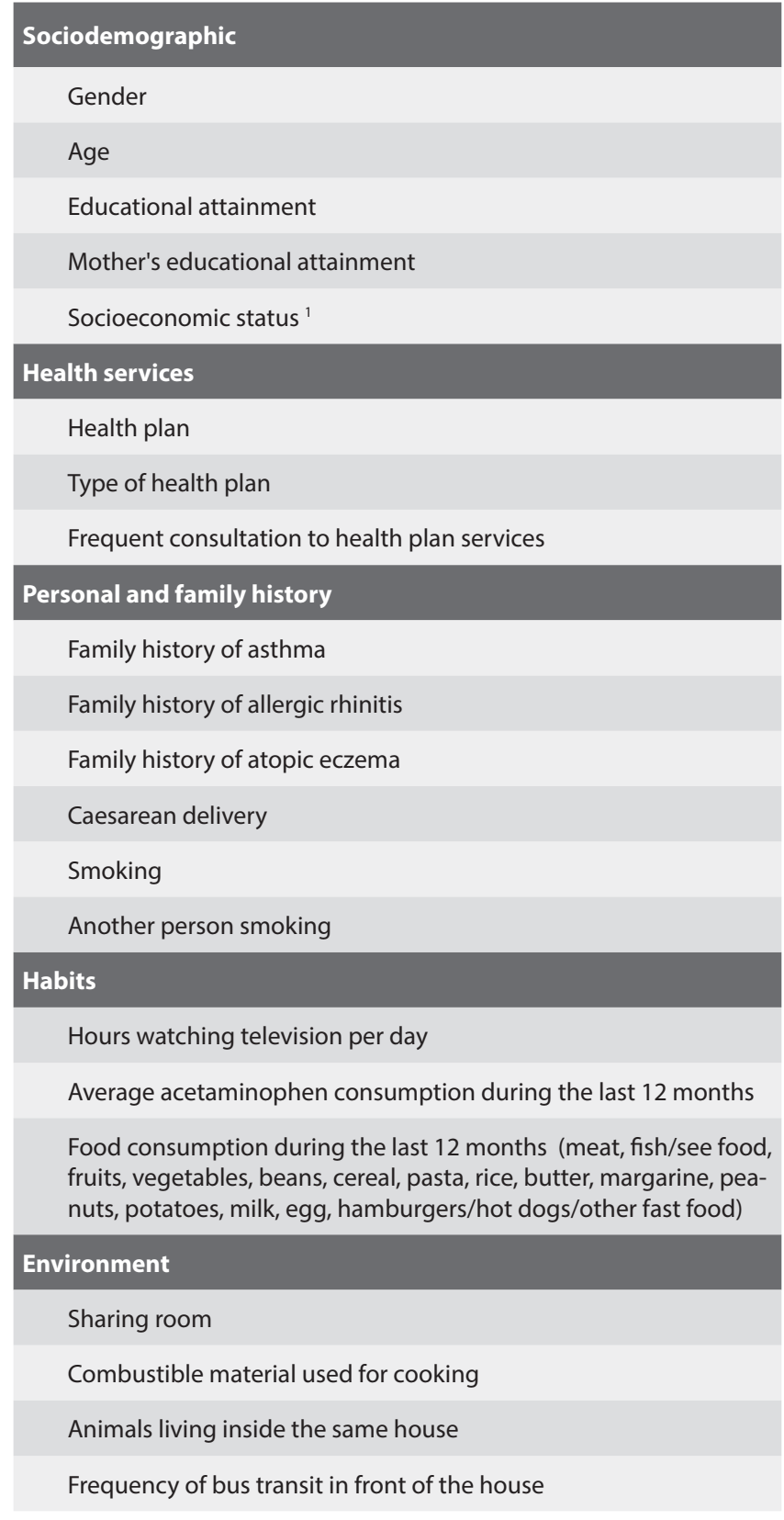

${ }^{1}$ Colombian population is divided in six socioeconomic strata considering urban characteristics such as population density, quality of public areas and housing characteristics (stratum one corresponds to the lowest and stratum six to the highest).

\section{Data management / statistical analysis}

Cases and controls were compared to identify possible factors associated with AR. The list of variables assessed for their association with AR was identical in both subpopulations (Table 1). Variables were individually evaluated on their association with AR to identify a broad range of explanatory variables that might be associated with AR in each subpopulation. Explanatory variables with a $p$-value $<0.15$ in the univariable analysis were kept for the multivariable weighted logistic regression model. For any variable, the category of response with the lowest prevalence of AR was chosen as the reference category. Gender and age were considered clinically important and used as adjustment variables in the multivariable model for both populations. Age was included as continuous variable.

Weighted logistic regression models were carried out separately for each sub-population. To determine which terms were significant, a hierarchical backward elimination approach was carried out, comparing the model with all interactions terms and the model without a particular interaction. Interactions for having a caesarean delivery with SES, as well as age and SES, were evaluated in each population. To assess the statistical significance of interaction terms, we used a single Chunk test ${ }^{(14)}$ comparing the full model that included all interactions terms and the model without these interactions terms. Variables not statistically significant during the backward elimination procedure were eliminated from the multivariable model. All of the analyses are presented as weighted statistics using the Taylor series linearization method for variance estimation ${ }^{(15)}$ using Stata Statistical Software for Windows, release 12 (Stata Corp., College Station, TX, USA). Two subpopulation analyses are presented: one for children/adolescents (participants aged 1-17) and the second one for adults (participants aged 18-59) as crude and adjusted odds ratios (OR) as well as $95 \%$ confidence intervals $(\mathrm{Cl})$.

\section{Results}

Out of the 5978 subjects in the cross-sectional survey, 1899 subjects were identified as cases and 3109 subjects were identified as controls. The remaining 970 subjects were excluded from this study based on the inclusion/exclusion criteria.

Table 2 shows the socio-demographic distribution of cases and controls in children/adolescents and adults. Table 3 and 4 show weighted percentages by city, age and gender in children/adolescents and adults, and OR of the crude association between possible related factors and AR symptoms during the twelve months previous to the survey date. Tables 5 and 6 show the statistically significant variables after multivariate analysis in children/adolescents and adults, respectively.

\section{Socio-demographic characteristics}

Mean age in the subpopulation of children/adolescents was 8.81 SE 0.245 (IC95\%; 8.33-9.29). The mean age in the adult population was 36.95 SE 0.245 (IC95\%; 36.47-37.43). In the adult population, the proportion of controls (68.0\%) was near double the proportion of cases (32.0\%). Gender distribution of the subpopulations studied was in accordance with the percentage of males and females within the Colombian census for $2009^{(16)}$. The majority of children/adolescents as well as the majority of 
Table 2. Socio-demographic characteristics of cases and controls by subpopulation.

\begin{tabular}{|c|c|c|c|c|c|c|c|c|}
\hline \multirow{3}{*}{ Variable } & \multicolumn{4}{|c|}{ Children/adolescents } & \multicolumn{4}{|c|}{ Adults } \\
\hline & $n$ & $\begin{array}{c}\text { Cases } \\
(\mathbf{n}=\mathbf{8 0 0})\end{array}$ & $\begin{array}{l}\text { Controls } \\
(n=776)\end{array}$ & p-value & $\mathbf{n}$ & $\begin{array}{c}\text { Cases } \\
(n=1004)\end{array}$ & $\begin{array}{l}\text { Controls } \\
(n=2149)\end{array}$ & p-value \\
\hline & & $\%$ & $\%$ & & & $\%$ & $\%$ & \\
\hline \multicolumn{9}{|l|}{ Gender } \\
\hline Male & 782 & 54.7 & 47.8 & 0.254 & 1219 & 42.0 & 50.8 & $<0.0001$ \\
\hline Female & 794 & 45.3 & 52.2 & & 2213 & 58.0 & 49.2 & \\
\hline \multicolumn{9}{|l|}{ Socioeconomic status } \\
\hline 1 and 2 (low) & 870 & 47.0 & 65.8 & 0.003 & 1670 & 44.3 & 49.2 & 0.060 \\
\hline 3 and 4 (middle) & 666 & 46.4 & 32.5 & & 1657 & 51.8 & 47.5 & \\
\hline 5 and 6 (high) & 40 & 6.1 & 1.7 & & 104 & 3.8 & 3.3 & \\
\hline \multicolumn{9}{|c|}{ Health insurance plan } \\
\hline Yes & 1479 & 92.3 & 95.6 & 0.158 & 3156 & 91.4 & 91.4 & 0.996 \\
\hline No & 73 & 7.7 & 4.4 & & 274 & 8.6 & 8.6 & \\
\hline \multicolumn{9}{|c|}{ Insurance plan of the enrolled } \\
\hline Contributive/Special & 1062 & 74.6 & 66.8 & 0.203 & 2072 & 69.2 & 65.8 & 0.083 \\
\hline Subsidized & 407 & 25.4 & 33.2 & & 1081 & 30.8 & 34.2 & \\
\hline
\end{tabular}

adults were enrolled in a health care insurance plan. The most frequent SES for cases and controls in both populations were low and middle status, also in accordance with the distribution of Colombian census and projections for $2009^{(17)}$ (Table 2).

\section{Associated factors}

Children/adolescents

Children/adolescents who reported a parent or a brother with AR or atopic eczema symptoms [OR $4.2(95 \mathrm{Cl} \% ; 2.4-7.1)$ and OR 2.6 (95Cl\%; 1.2-5.8) respectively] had higher odds of having AR symptoms, in comparison with children or adolescents who reported not having parents or brothers with AR or atopic eczema. Children/adolescents taking acetaminophen at least once per month on average for the last twelve months, had increased odds of AR symptoms [OR 5.4 (95Cl\%; 2.5-11.9)] in comparison with children/adolescents that never consumed acetaminophen during the twelve months previous to the survey date.

With regard to food consumption, we found that children/adolescents who reported consumption of hamburgers/hot dogs or other fast food items at least once per week had increased odds of reporting AR symptoms [OR 2.3 (95Cl\%; 1.3-4.0)] in comparison to children/adolescents that occasionally or never consumed hamburgers/hot dogs or other fast foods. In contrast, children/adolescents consuming cereals at least once per week had lower odds of reporting AR symptoms [OR 0.3 (95Cl\%; 0.10.9)] in comparison with children/adolescents that occasionally or never consumed cereals for the twelve months period prior to the survey date. Also, children/adolescents that reported natural gas/gas cylinder/wood/trash for cooking had lower odds of reported AR symptoms [OR 0.4 (95Cl\%; 0.2-0.9)] in comparison with children/adolescents that reported use of electricity for cooking.

Children/adolescents of middle-class SES (three and four) and high SES (five and six) had increased odds of reporting AR symptoms [OR 2.0 (95Cl\%; 1.2-3.3) and OR 5.4 (95Cl\%; 1.2-25.2), respectively] in comparison with children/adolescents of low SES (class one and two). Children/adolescents that were born by caesarean delivery had increased odds of reporting AR symptoms [OR 2.7 (95Cl\%; 1.2-5.8)] in comparison with children/ adolescents that were not born by caesarean delivery (Table 3).

After simultaneous adjustment by gender, age, fuel source used for cooking, history of AR in parents or brothers, history of atopic eczema in parents and brothers, acetaminophen consumption, cereal consumption, health care plan and SES, we found significant associations in the multivariate model among children/ adolescents who reported a history of parents or brothers with AR compared with children/adolescents without family history of AR [OR 3.7 (95\%Cl; 2.0-6.7). Consuming acetaminophen at least once per week [OR 7.4 (95\%Cl; 2.9-18.5)] and middle and high SES [OR 2.1 (95\%Cl; 1.2-3.6) and OR 5.6 (95\%Cl; 1.2-26.4, 
Peñaranda et al.

Table 3. Weighted percentages by city, age and gender of children/adolescents characteristics and OR of the association between possible related factors and AR.

\begin{tabular}{|c|c|c|c|c|c|c|c|}
\hline \multirow{2}{*}{ Variable } & \multirow[b]{2}{*}{$\mathbf{n}$} & \multicolumn{2}{|c|}{ Cases } & \multicolumn{2}{|c|}{ Controls } & \multirow{2}{*}{ Crude OR } & \multirow{2}{*}{ (OR Cl 95\% } \\
\hline & & $\%$ & $95 \% \mathrm{Cl}$ & $\%$ & $95 \% \mathrm{Cl}$ & & \\
\hline \multicolumn{8}{|l|}{ Gender } \\
\hline Male & 782 & 54.7 & $(44.8-64.2)$ & 47.8 & $(41.3-54.3)$ & 1.0 & \\
\hline Female & 794 & 45.3 & $(35.8-55.2)$ & 52.2 & $(45.7-58-7)$ & 0.8 & $(0.5-1.2)$ \\
\hline \multicolumn{8}{|c|}{ Combustible material used for cooking } \\
\hline Electricity & 79 & 4.8 & $(2.7-8.6)$ & 2.0 & $(1.2-3.3)$ & 1.0 & \\
\hline $\begin{array}{l}\text { Natural gas/gas cylinder/wood/ } \\
\text { trash }\end{array}$ & 1489 & 95.2 & $(91.4-97.3)$ & 98.0 & $(96.7-98.8)$ & 0.4 & $(0.2-0.9)$ \\
\hline \multicolumn{8}{|c|}{ Socioeconomic status of the residence } \\
\hline 1 and 2 (low) & 870 & 47.0 & $(37.4-56.8)$ & 65.8 & $(59.5-71.6)$ & 1.0 & \\
\hline 3 and 4 (middle) & 666 & 46.4 & $(36.8-56.4)$ & 32.5 & $(26.8-38.7)$ & 2.0 & $(1.2-3.3)$ \\
\hline 5 and 6 (high) & 40 & 6.6 & $(2.5-16.5)$ & 1.7 & $(0.6-5.0)$ & 5.4 & $(1.2-25.2)$ \\
\hline \multicolumn{8}{|l|}{ Family history of AR } \\
\hline Yes & 488 & 44.2 & $(33.9-54.9)$ & 15.9 & $(12.1-20.6)$ & 4.2 & $(2.4-7.1)$ \\
\hline No & 992 & 55.8 & $(45.1-66.1)$ & 84.1 & $(79.4-87.9)$ & 1.0 & \\
\hline \multicolumn{8}{|l|}{ Family history of atopic eczema } \\
\hline Yes & 198 & 24.3 & $(14.4-38.0)$ & 10.8 & $(7.1-16.1)$ & 2.6 & $(1.2-5.8)$ \\
\hline No & 1250 & 75.7 & $(62.0-85.6)$ & 89.2 & $(83.9-92.9)$ & 1.0 & \\
\hline \multicolumn{8}{|c|}{ Average acetaminophen consumption } \\
\hline At least once per week & 293 & 18.4 & $(14.0-23.9)$ & 12.7 & $(8.7-18.2)$ & 4.5 & $(2.0-10.2)$ \\
\hline At least once per month & 492 & 41.3 & $(31.7-51.5)$ & 23.9 & $(19.0-29.6)$ & 5.4 & $(2.5-11.9)$ \\
\hline At least four times per year & 469 & 29.6 & $(20.5-40.8)$ & 35.7 & $(29.7-42.3)$ & 1.5 & $(0.6-3.7)$ \\
\hline At least once per year & 157 & 5.9 & $(3.4-10.2)$ & 12.5 & $(9.0-17.1)$ & 2.6 & $(1.1-6.0)$ \\
\hline Never & 165 & 4.8 & $(2.7-8.5)$ & 15.1 & $(11.0-20.4)$ & 1.0 & \\
\hline \multicolumn{8}{|c|}{ Average consumption of hamburger/hot dogs or other fast food during the 12 months period to the survey date } \\
\hline Ocasionally or never & 1088 & 63.7 & $(53.2-73.0)$ & 80.2 & $(74.2-85.1)$ & 1 & \\
\hline One or two times per week & 488 & 36.4 & $(27.0-46.8)$ & 19.8 & $(14.9-25.8)$ & 2.3 & $(1.3-4.0)$ \\
\hline \multicolumn{8}{|c|}{ Average consumption cereal during the 12 months period to the survey date } \\
\hline Occasionally or never & 107 & 12.8 & $(6.4-23.9)$ & 4.7 & $(2.4-8.9)$ & 1.0 & \\
\hline One or two times per week & 1469 & 87.3 & $(76.1-93.6)$ & 95.3 & $(91.1-97.6)$ & 0.3 & $(0.1-0.9)$ \\
\hline \multicolumn{8}{|l|}{ Caesarean delivery } \\
\hline Yes & 553 & 31.6 & $(23.0-41.5)$ & 29.6 & $(24.3-35.5)$ & 2.7 & $(1.2-5.8)$ \\
\hline No & 992 & 68.4 & $(58.5-77.0)$ & 70.4 & $(64.5-75.7)$ & 1.0 & \\
\hline
\end{tabular}


Table 4. Weighted percentages by city, age and gender of adults' characteristics and OR of the association between possible related factors and AR.

\begin{tabular}{|c|c|c|c|c|c|c|c|}
\hline \multirow{2}{*}{ Variable } & \multirow{2}{*}{$\mathbf{n}$} & \multicolumn{2}{|c|}{ Cases } & \multicolumn{2}{|c|}{ Controls } & \multirow{2}{*}{ Crude OR } & \multirow{2}{*}{ (OR Cl 95\%) } \\
\hline & & $\%$ & $95 \% \mathrm{Cl}$ & $\%$ & $95 \% \mathrm{Cl}$ & & \\
\hline \multicolumn{8}{|l|}{ Gender } \\
\hline Male & 1219 & 42.0 & $(38.7-45.4)$ & 50.8 & $(48.6-53.0)$ & 1.0 & \\
\hline Female & 2213 & 58.0 & $(54.6-61.3)$ & 49.2 & $(47.0-51.4)$ & 1.4 & $(1.2-1.7)$ \\
\hline \multicolumn{8}{|l|}{ Educational attainment } \\
\hline No education/Elementary school & 815 & 20.3 & $(17.8-23.0)$ & 25.9 & $(24.0-27.8)$ & 1.0 & \\
\hline Middle/ High school & 1692 & 47.8 & $(44.6-51.1)$ & 48.9 & $(46.7-51-1)$ & 1.2 & $(1.0-1.5)$ \\
\hline Technician/University/Postgrad & 891 & 31.9 & $(28.9-35.0)$ & 25.3 & $(23.3-27.3)$ & 1.6 & $(1.3-2.0)$ \\
\hline \multicolumn{8}{|l|}{ Mother's educational attainment } \\
\hline No education/Elementary school & 2027 & 63.7 & $(60.3-67.0)$ & 68.7 & $(66.4-70.9)$ & 1.0 & \\
\hline Middle/High school & 696 & 23.2 & $(20.5-26.3)$ & 23.4 & $(21.4-25.5)$ & 1.1 & $(0.9-1.3)$ \\
\hline Technician/University/Postgrad & 249 & 13.1 & $(10.8-15.8)$ & 7.9 & $(6.7-9.4)$ & 1.8 & $(1.3-2.4)$ \\
\hline \multicolumn{8}{|l|}{ Animals living in the same house } \\
\hline Yes & 1566 & 47.7 & $(44.5-51.0)$ & 43.8 & $(41.6-46.0)$ & 1.2 & $(1.0-1.4)$ \\
\hline No & 1866 & 52.3 & $(49.0-55.5)$ & 56.2 & $(54.0-58.4)$ & 1.0 & \\
\hline \multicolumn{8}{|l|}{ Asthma in parents or brothers } \\
\hline Yes & 589 & 22.5 & $(19.9-25.3)$ & 13.5 & $(12.0-15.0)$ & 1.9 & $(1.5-2.3)$ \\
\hline No & 2822 & 77.5 & $(74.7-80.1)$ & 86.5 & $(85.0-88.0)$ & 1.0 & \\
\hline \multicolumn{8}{|l|}{ AR in parents or brothers } \\
\hline Yes & 556 & 30.2 & $(27.3-33.3)$ & 9.2 & $(8.0-10.6)$ & 4.3 & $(3.5-5.2)$ \\
\hline No & 2838 & 69.8 & $(66.7-72.7)$ & 90.8 & $(89.4-92.0)$ & 1.0 & \\
\hline \multicolumn{8}{|c|}{ Atopic eczema in parents or brothers } \\
\hline Yes & 236 & 14.5 & $(12.3-17.0)$ & 3.7 & $(3.0-4.7)$ & 4.4 & $(3.2-5.9)$ \\
\hline No & 3160 & 85.5 & $(83.0-87.7)$ & 96.3 & $(95.4-97.0)$ & 1.0 & \\
\hline \multicolumn{8}{|c|}{ Average acetaminophen consumption } \\
\hline At least once per week & 788 & 27.8 & $(25.1-30.7)$ & 17.7 & $(16.2-19.4)$ & 2.3 & $(1.8-2.9)$ \\
\hline At least once per month & 939 & 29.7 & $(26.9-32.8)$ & 23.9 & $(22.2-25.8)$ & 1.8 & $(1.4-2.3)$ \\
\hline At least four times per year & 712 & 19.0 & $(16.5-21.7)$ & 22.8 & $(21.0-24.7)$ & 0.8 & $(0.6-1.2)$ \\
\hline At least once per year & 271 & 5.5 & $(4.1-7.2)$ & 9.7 & $(8.5-11.2)$ & 1.2 & $(0.9-1.6)$ \\
\hline Never & 715 & 18.0 & $(15.5-20.7)$ & 25.8 & $(23.9-27.9)$ & 1.0 & \\
\hline \multicolumn{8}{|c|}{ Average consumption of meat during the 12 months period to the survey date } \\
\hline Ocasionally or never & 117 & 4.7 & $(3.4-6.4)$ & 3.0 & $(2.4-3.9)$ & 1.0 & \\
\hline One or two times per week & 3315 & 95.3 & $(93.6-96.6)$ & 97.0 & $(96.1-97.6)$ & 0.6 & $(0.42-0.96)$ \\
\hline \multicolumn{8}{|c|}{ Average consumption of beans during the 12 months period to the survey date } \\
\hline Ocasionally or never & 302 & 10.8 & $(8.9-13.9)$ & 8.4 & $(7.2-9.7)$ & 1.0 & \\
\hline One or two times per week & 3129 & 89.2 & $(87.0-91.1)$ & 91.6 & $(90.3-92.9)$ & 0.8 & $(0.6-0.99)$ \\
\hline
\end{tabular}


Table 4. Continued....

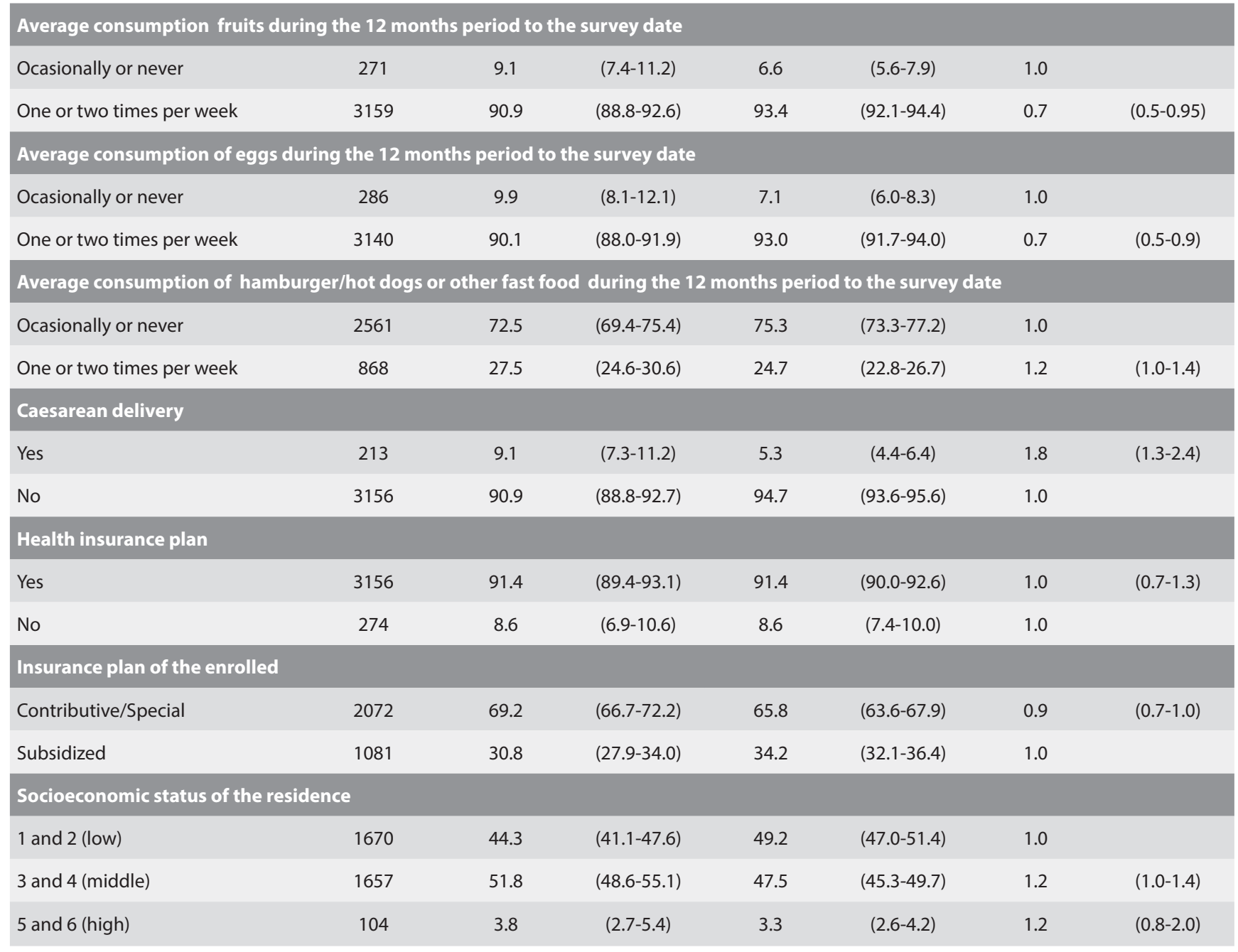

respectively)] were also significant.

Children/adolescents who reported cereal consumption at least once per week had a lower odds of reporting AR symptoms [OR 0.3 (95\% Cl; 0.1-0.9)] compared to children/adolescents who occasionally or never consumed cereal during the twelve months prior to the survey date in the multivariable model (Table 5).

Adults

Women had higher odds for AR symptoms [OR 1.4 (95Cl\%; 1.2-1.7)] than men. Adults that reported educational attainment and mother's educational attainment at Technician/University/ Postgrad level had higher odds for reporting AR symptoms [OR $1.6(95 \% \mathrm{Cl} ; 1.3-2.0)$ and $\mathrm{OR} 1.8(95 \mathrm{Cl} \% ; 1.3-2.4)$ respectively] in comparison with adults that reported no education or elementary education and mothers without education or elementary education. Adults who reported animals living in the same house, who reported any parent or brother with asthma, or AR or atopic eczema symptoms or who reported caesarean delivery also had higher odds for reporting AR symptoms in comparison with their counterparts (Table 4).

Adults taking acetaminophen at least once per week and at least once per month had increased odds for AR symptoms [OR 2.3 (95Cl\%; 1.8-2.9) and OR 1.8 (95Cl\%; 1.4-2.3)] in comparison with adults that never consumed acetaminophen during the twelve months previous to the survey date. Adults living in middle SES had higher odds of AR symptoms [OR 1.2 (95Cl\%; 1.03-1.4)] in comparison to adults living in low SES.

With regard to food exposure, adults consuming hamburgers/ hot dogs or other fast food at least once a week for the twelve months period to the survey date had higher odds of reporting AR symptoms [OR 1.2 (95Cl\%; 1.0-1.4)] in comparison with those reporting occasional consumption or never. Adults consuming meat, beans, fruit and eggs at least once per week had reduced odds of reporting AR symptoms [OR 0.6 (95CI\%; 0.4-0.9), OR 0.8 (95Cl\%; 0.6-0.9), OR 0.7 (95Cl\%; 0.5-1.0) and OR 0.7 (95Cl\%; 0.50.9)], in comparison with their counterparts (Table 4).

After simultaneous adjustment for gender, age, asthma in 
Table 5. Children/adolescents' significant associated factors with AR symptoms after multivariate analysis.

\begin{tabular}{|c|c|c|}
\hline Variable & Adjusted OR $^{1}$ & (OR CI95\%) \\
\hline \multicolumn{3}{|l|}{ Combustible material for cooking } \\
\hline Electricity & 1.0 & \\
\hline Natural gas/gas cylinder/other ${ }^{2}$ & 0.3 & $(0.1-0.9)$ \\
\hline \multicolumn{3}{|l|}{ AR in parents or brothers } \\
\hline Yes & 3.7 & $(2.0-6.7)$ \\
\hline No & 1.0 & \\
\hline \multicolumn{3}{|c|}{ Acetaminophen consumption frequency } \\
\hline At least once per week & 7.4 & $(2.9-18.5)$ \\
\hline At least once per month & 5.3 & $(2.2-12.9)$ \\
\hline Never & 1.0 & \\
\hline \multicolumn{3}{|c|}{ Cereal consumption during the last 12 months } \\
\hline Ocasionally or never & 1.0 & \\
\hline At least once per week & 0.3 & $(0.1-0.9)$ \\
\hline \multicolumn{3}{|c|}{ Socioeconomic Estratum of the residence } \\
\hline 1 and 2 & 1.0 & \\
\hline 3 and 4 & 2.1 & $(1.2-3.6)$ \\
\hline 5 and 6 & 5.6 & $(1.2-26.4)$ \\
\hline
\end{tabular}

${ }^{1}$ Adjusted by age, gender, history of atopic eczema in parents or brothers and health care plan. ${ }^{2}$ Firewood, gasoil, waste.

parents or brothers, AR in parents or brothers, atopic eczema in parents or brothers, caesarean delivery, acetaminophen consumption, and egg consumption, we found that women had higher odds of reporting AR symptoms than men [OR 1.2; (95\% Cl, 1.0-1.5)]. Adjusted odds were also high for, adults who reported a history of parents or brothers with asthma, AR and atopic eczema than their reference category. Adults consuming acetaminophen at least once per week had higher adjusted odds of reporting AR symptoms as well as adults who reported being born by caesarean delivery than their counterparts. Adults who reported eggs consumption at least once per week had lower odds of reporting AR symptoms [OR 0.7 (95Cl\%; 0.5-0.9)] as compared with adults who occasionally or never consumed eggs during the twelve months previous to the survey date, respectively (Table 6).

\section{Discussion}

To our knowledge, the present study is the first study in both Colombia and Latin America to simultaneously assess potential factors associated with AR in a large sample of subjects aged 1 to 17 years and 18 to 59 years.

The results of this study confirm the association between gender and AR symptoms in the adult population; women were more likely to report symptoms, as previous observational studies have reported ${ }^{(18,19)}$. Previous cohort ${ }^{(20)}$ and cross-sectional ${ }^{(19,21)}$ studies have shown higher prevalence of AR in women, although this difference was not statistically significant. The European Community Respiratory Health Study (ECRHS II) ${ }^{(22)}$ and the study of Kurukulaaratchy et al ${ }^{(20)}$ found that although women suffer less frequently from AR during infancy and adolescence than do men, their risk increases during adulthood. Hormonal factors have been proposed as protective in women during adolescence, when hypothalamic-pituitary and sexual hormones modulate the immunological system ${ }^{(23)}$. Besides this protection, it has also been suggested that adult women are highly susceptible to indoor pollutants, smoking and sedentary lifestyle, as factors associated with non-allergic rhinitis ${ }^{(20)}$.

Our findings also provide evidence for an association between family history of allergic diseases and the presence of AR symptoms. Results showed an association between parents or brothers with AR for both populations. Conversely, asthma and atopic eczema in parents or brothers were associated factors for AR only in adults. Family history of allergic disease has been widely documented by cross-sectional studies ${ }^{(24-26)}$ as well as by cohort studies ${ }^{(22,27,28)}$. A study in Germany followed 467 children over time ${ }^{(27)}$ showed that the period prevalence for twelve months rose from $6 \%$ at the age of three years to $24 \%$ at the age of thirteen in children without a family history of allergies. For children with a positive history of at least one parent suffering from allergic diseases, prevalence rose from $13 \%$ at the age of three years to $44 \%$ at the age of thirteen. A 23-year follow-up study, showed not only an increase in allergy as the population grew older, but also suggested that allergies change throughout life ${ }^{(28)}$. According to Settipane et al., people suffering from AR in previous years have an increased risk of suffering from asthma in adulthood more than threefold, compared with those without $A R^{(28)}$.

We found an association between AR and SES in the children/ adolescents subpopulation with low precision due to wide confidence intervals. We recognize that the proportion of subjects in our study are low in higher SES in both subpopulations; however, this distribution is consistent with the Colombian distribution of the population where stratum 5 and 6 both represent a very low proportion of the population (SES five represents $1.9 \%$ of the Colombian population and SES six represents $1.2 \%$ of the Colombian population) ${ }^{(17)}$. Nevertheless, other studies carried out in school children (6 to 7 years and 13 to 14 years) in Bogotá city ${ }^{(9)}$ and abroad ${ }^{(29)}$ suggest similar associations ${ }^{(17)}$; 
Tabla 6. Adults' significant associated factors with AR symptoms after multivariate analysis

\begin{tabular}{|c|c|c|}
\hline Variable & Adjusted OR ${ }^{1}$ & (OR Cl95\%) \\
\hline \multicolumn{3}{|l|}{ Gender } \\
\hline Male & 1.0 & \\
\hline Female & 1.2 & $(1.0-1.5)$ \\
\hline \multicolumn{3}{|c|}{ Asthma in parents or brothers } \\
\hline Yes & 1.3 & $(1.1-1.7)$ \\
\hline No & 1.0 & \\
\hline \multicolumn{3}{|l|}{ AR in parents or brothers } \\
\hline Yes & 3.2 & $(2.5-4.0)$ \\
\hline One or two times per week & 1.0 & \\
\hline \multicolumn{3}{|c|}{ Atopic eczema in parents or brothers } \\
\hline Yes & 2.9 & $(2.1-4.1)$ \\
\hline No & 1.0 & \\
\hline \multicolumn{3}{|l|}{ Caesarean delivery } \\
\hline Yes & 1.0 & \\
\hline No & 2.1 & $(1.2-3.6)$ \\
\hline \multicolumn{3}{|c|}{ Acetaminophen consumption frequency } \\
\hline At least once per week & 1.9 & $(1.4-2.4)$ \\
\hline At least once per month & 1.7 & $(1.3-2.2)$ \\
\hline Never & 1.0 & \\
\hline \multicolumn{3}{|c|}{ Eggs consumption during the last 12 months } \\
\hline Ocasionally or never & 1.0 & \\
\hline At least once per week & 0.7 & $(0.5-0.9)$ \\
\hline
\end{tabular}

SES could influence the possibility of more frequent diagnosis, treatment, and disease monitoring according to the ecological study by Stewart et al. ${ }^{(30)}$.

Children/adolescents that reported cereal consumption and adults eating eggs at least once per week were less likely to report AR symptoms. Previous studies have described associations between diet and allergic diseases or allergic sensitization (31). One of the strongest theories argues that a western life style characterized by the frequent use of antibiotics and medicines, hyper-caloric diets, processed food intake, small families, and better hygiene are driving changes in the intestinal micro-flora and interfering with the development of immune tolerance (32-34). Cereal consumption by children and egg consumption by adults suggest diets rich in antioxidants that may protect against allergic diseases ${ }^{(32)}$. However, we did not explore if participants avoided food consumption due to food allergies, as this was not measured in our questionnaire. Food allergies occur in about $1 \%$ to $2 \%$ of adults in the general population and about $4 \%$ in children less than 18 years of age ${ }^{(35)}$. There is a close association and a higher incidence of food allergy in individuals with other atopic disorders than in the general population, as showed in a French study that assessed the prevalence of food allergy and its association with respiratory manifestations among school children (asthma and AR). The study reported that children aged 9 to 11 had an odds of 4.0 (CI 95\% 2.4-6.6) of reporting food allergy and past year AR symptoms under ISAAC definition, when compared to children without food allergy. The authors suggested food allergy as a first step in the "allergic march" leading to the development of allergic asthma or AR ${ }^{(36)}$. Our study was aimed as an explorative analysis of dietary habits and AR; therefore, food allergies were not asked about, and we are not able to conclude anything about the role of food allergy as an explanation for the avoidance of selected foods.

Our results also showed in adults significant associations with caesarean delivery. Few studies have assessed the association between AR, allergies and asthma and caesarean delivery, but the populations studied were children ${ }^{(9,37)}$. These studies also showed a greater risk for asthma in children born by caesarean. The study by Almqvist et al. showed that after stratified analysis, the association only remained significant with emergency caesarean interventions, concluding that caesarean delivery per se does not increase the risk for asthma, but that asthma could be associated more with the health of mother's and foetal conditions before the delivery, also indications for the caesarean $\left.{ }^{(37}\right)$. Our study is to our knowledge the first study that shows the association between adults with history of caesarean delivery and AR symptoms. Following the hypothesis of Almqvist on the indication of the caesarean, it is possible that in Colombia 17 years ago, the number of caesarean deliveries were more related with emergency caesareans compared with the caesareans currently carried out. A Colombian study from 1995 to 2005, showed a rise in the percentage of caesarean deliveries, from $22.5 \%$ to $30.3 \%$ for that period of time. The increase in the number of caesarean deliveries for Colombia and the Latin-American region can be explained by the "medicalization" of the delivery. Patients and doctors now may choose the date for delivery based on convenience ${ }^{(38)}$.

Our study found positive associations between symptoms of AR and acetaminophen consumption, both for children/ adolescents and adults. This adds support to acetaminophen as an independent factor associated with $A R^{(39)}$. During the 1990 's, acetaminophen consumption was associated with the development of allergy in children and adults ${ }^{(40-42)}$. Mechanisms 
that help explain this association deal with the depletion of glutathione, an anti-oxidative molecule present at the lung and respiratory mucosae ${ }^{(43,44)}$. The indirect inflammatory response increases the Th2 response and favours the allergic disorders ${ }^{(45)}$. A second mechanism may be the inhibition of cyclooxygenase ${ }^{(46)}$, which is required for prostaglandin production in the inflammation cascade, through the regular use of acetaminophen. This would be explained by acetaminophen being recognized as an antigen, with increases in immunoglobulin $\mathrm{E}$ and histamine levels ${ }^{(47,48)}$. However, we cannot rule out confounding by the indication for acetaminophen as an alternative explanation ${ }^{(49,50)}$. A cohort study in Australia followed children with family history of allergic diseases and found that after adjustment by respiratory disease history in early ages, the association between paracetamol and allergic diseases disappears. The cross-sectional nature of our study did not allow us to test this alternative explanation.

\section{Conclusion}

The present study identified factors associated with AR symptoms in Colombia. These findings suggest the presence of cultural, environmental and familiar factors in a large sample of children and adults in six cities, where factors associated with AR were previously unknown. The study also provides the basis for future research to confirm our findings, as well as research on likely pathways associated with the identified factors.

\section{Strengths and weaknesses}

This is the first large scale study investigating the association between individual, familial, cultural and socioeconomic factors and $A R$ in a wide range of Colombian urban dwellers. This study described associations that may help explain the patterns of relationship between different variables and AR symptoms in children/adolescents and adults.

The limitations of this study also need to be considered. First, we used questionnaires to assess outcomes. Self-completed questionnaires by adolescents and questionnaires filled with the help of an interviewer for parents of small children and adults might lead to diagnostic misclassification that would reduce the chance of identifying associations. In addition, recall bias is a possibility, which might potentially make allergic subjects more likely to report higher frequency of some factors. This would lead to overestimation of some relationships. Secondly, the cross-sectional nature of the study limits inferences, and a longitudinal design should have been better suited to test some associations. Finally, this study was based only in urban settlements, limiting inferences to rural areas. However, this study involved a representative population of the major cities in Colombia, allowing us to represent nearly $80 \%$ of the population (51).

\section{Acknowledgements}

The authors wish to thank all subjects that participated in the study, as well as research assistants and all personnel involved in field work, specially Alberto Jurado and his team, Angelica Prieto, and Cristina Venegas. This work was made possible by funding from Colciencias grant 540-2008, and by unrestricted research grants from MSD, Astra-Zeneca, GSK, and Sanofi-Aventis. Dr Pérez was supported by a research supplement (Grant 3R37CA057030-20S1) from NCl during the conduction of this study.

\section{Authorship contribution}

AP participated in interpretation of data and drafted the manuscript; EG participated in the conception, design, interpretation, analysis of data, and helped draft the manuscript. AMB participated in the design, coordinated data collection, helped with interpretation and data analysis and reviewed the manuscript. MAR participated in the design of the study, helped with planning data collection, performed the statistical analysis and revised the manuscript. AP participated in the design of the study, overall planning of data collection, helped with statistical analysis and revised the manuscript. MXR participated in the design, analysis of data and revising the manuscript. LC participated in the conception, design, interpretation, analysis of data, and revising the manuscript. RJD conceived the study and had primary responsibility for design, overall planning, interpretation, and manuscript revision.

\section{Conflict of interest}

All of the authors declare no conflicts of interests related with this work.

\section{References}

1. Björkstén B, Clayton T, Ellwood P, Stewart A, Strachan D. Worldwide time trends for symptoms of rhinitis and conjunctivitis: Phase III of the International Study of Asthma and Allergies in Childhood. Pediatr Allergy Immunol 2008;19:110-24.

2. Bousquet J, Schünemann HJ, Samolinski B, Demoly P, Baena-Cagnani CE, Bachert $C$, et al. Allergic Rhinitis and its Impact on
Asthma (ARIA): achievements in 10 years and future needs. J Allergy Clin Immunol 2012;130:1049-62.

3. Lagos J, Marshall GD. Montelukast in the management of allergic rhinitis. Ther Clin Risk Manag 2007;3:327-32.

4. Meltzer EO. Allergic rhinitis: the impact of discordant perspectives of patient and physician on treatment decisions. Clin Ther 2007;29:1428-40
5. Neffen H, Mello JF, Sole D, Naspitz CK, Dodero AE, Garza HL, et al. Nasal allergies in the Latin American population: results from the Allergies in Latin America survey. Allergy Asthma Proc 2010;31 Suppl 1:S9-27.

6. Yepes-Nuñez JJ, Gómez-García C, EspinosaHerrera Y, Cardona-Villa R. Health-related quality of life in children and adults with respiratory allergy in Colombia: prospective study. Allergol immunopathol 2012;40:379- 
84.

7. Meltzer EO, Blaiss M, Derebery MJ, Mahr T, Gordon BR, Sheth KK, et al. Burden of allergic rhinitis: results from the Pediatric Allergies in America survey. J Allergy Clin Immunol 2009;124:S43-70.

8. Chong Neto HJ, Rosário NA, Solé D. Asthma and Rhinitis in South America: How Different They are From Other Parts of the World. Allergy Asthma Immunol Res 2012:4:62-7.

9. Peñaranda A, Aristizabal G, Garcia E, Vasquez C, Rodriguez-martinez CE, Satizába CL. Allergic rhinitis and associated factors in schoolchildren from Bogotá, Colombia. Rhinology 2012;50:122-8.

10. Dennis R, Caraballo L, Garcia E, Caballero A, Aristizabal G, Cordoba H, et al. Asthma and other allergic conditions in Colombia: a study in 6 cities. AnnAllergy Asthma Immunol 2004;93:568-74.

11. Dennis RJ, Caraballo L, García E, Rojas MX, Rondon MA, Pérez A, et al. Prevalence of asthma and other allergic conditions in Colombia 2009-2010: a cross-sectional study. BMC Pulm Med 2012;12:17

12. Asher I, Keil U, Anderson H, Beasley R, Crane J, Martinez F, et al. International Study of Asthma and Allergies in Childhood (ISAAC) rationale and methods. Eur Respir J 1995;8:483-91.

13. Ellwood P, Asher MI, Beasley R, Clayton TO, Stewart a W. The international study of asthma and allergies in childhood (ISAAC): phase three rationale and methods. Int J Tuberc Lung Dis 2005:9:10-6.

14. Kleinbaum D, Klein M. II. Interaction Assessment Stage. In: M. Gail, K. Krickeberg, J.M. Samet, A. Tsiatis WW, editor. Logistic Regression A Self-Learning Text. New York: Springer; 2010. page 207-10.

15. Woodruff RS. A Simple Method for Approximating the Variance of a Complicated Estimate. J. Am. Stat. Assoc.1971;66:411-4.

16. Departamento Administrativo Nacional de Estadística (DANE). Proyecciones de Población departamentales y municipales por área [Internet]. 2009;Available from: https://www.dane. gov.co/files/investigaciones/poblacion/ proyepobla06_20/7Proyecciones_poblacion.pdf

17. Ministerio de Hacienda y Crédito Público. Documento Conpes 3386 [Internet]. [cited 2015 Apr 30];1-30. Available from: http:// scholar.google.com/scholar?hl=en\&btnG $=S$ earch\&q=intitle:Consejo+Nacional+de+Polí tica+Económica+y+Social\#0

18. Arshad SH, Karmaus W, Raza A, Kurukulaaratchy RJ, Matthews SM, Holloway JW, et al. The effect of parental allergy on childhood allergic diseases depends on the sex of the child. J Allergy Clin Immunol 2012;130:427-34.e6.

19. Cingi C, Topuz B, Songu M, Kara CO, Ural A, Yaz A, et al. Prevalence of allergic rhinitis among the adult population in Turkey. Acta
Otolaryngol 2010;130:600-6.

20. Kurukulaaratchy RJ, Karmaus W, Raza A, Matthews S, Roberts G, Arshad SH. The influence of gender and atopy on the natural history of rhinitis in the first 18 years of life. Clin Exp allergy 2011;41:851-9.

21. Westman $M$, Kull I, Lind T, Melén E, Stjärne $P$, Toskala $E$, et al. The link between parental allergy and offspring allergic and nonallergic rhinitis. Allergy Eur J Allergy Clin Immunol 2013:68:1571-8.

22. Matheson MC, Dharmage SC, Abramson MJ, Walters EH, Sunyer J, de Marco R, et al. Early-life risk factors and incidence of rhinitis: results from the European Community Respiratory Health Study--an international population-based cohort study. J Allergy Clin Immunol 2011;128:816-23.e5.

23. Govaere E, Van Gysel D, Massa G, Verhamme KMC, Doli E, De Baets F. The influence of age and gender on sensitization to aero-allergens. Pediatr Allergy Immunol 2007;18:6718.

24. Dold S, Wjst M, von Mutius E, Reitmeir P, Stiepel E. Genetic risk for asthma, allergic rhinitis, and atopic dermatitis. Arch Dis Child 1992;67:1018-22.

25. Pac-sa MR, Museros-recatala L, Arnedopena A, Bellido-blasco JB, Puig-barberà J, Artero-sivera A. Factores de riesgo de síntomas de rinitis alérgica en adolescentes de Castellón, España. Rev Panam Salud Publica 2008;23:333-41

26. Torres-Borrego J, Molina-Terán AB, MontesMendoza C. Prevalence and associated factors of allergic rhinitis and atopic dermatitis in children. Allergol immunopathol 2008;36:90-100.

27. Keil T, Bockelbrink A, Reich A, Hoffmann U, Kamin W, Forster J, et al. The natural history of allergic rhinitis in childhood. Pediatr Allergy Immunol 2010;21:962-9.

28. Settipane RJ, Hagy GW, Settipane G a. Longterm risk factors for developing asthma and allergic rhinitis: a 23-year follow-up study of college students. Allergy Proc 1994;15:21-5.

29. Bråbäck L, Hjern a, Rasmussen F. Social class in asthma and allergic rhinitis: a national cohort study over three decades. Eur Respir J Off J Eur Soc Clin Respir Physiol 2005;26:1064-8.

30. Stewart AW, Mitchell E, Pearce N, Strachan DP, Weiland SK. The relationship of per capita gross national product to the prevalence of symptoms of asthma and other atopic diseases in children (ISAAC). Int J Epidemiol 2001;30:173-9.

31. Ellwood P, Asher MI, García-Marcos L, Williams H, Keil U, Robertson C, et al. Do fast foods cause asthma, rhinoconjunctivitis and eczema? Global findings from the International Study of Asthma and Allergies in Childhood (ISAAC) Phase Three. Thorax 2013;68:351-60

32. Alm JS, Swartz J, Lilja G, Scheynius A, Pershagen G. Atopy in children of families with an anthroposophic lifestyle. Lancet 1999;353:1485-8.
33. Noverr MC, Huffnagle GB. Does the microbiota regulate immune responses outside the gut? Trends Microbiol 2004;12:562-8.

34. Strachan DP. Hay fever, hygiene, and household size. Br Med J 1989;299:1259-60.

35. Tan R a., Corren J. The Relationship of Rhinitis and Asthma, Sinusitis, Food Allergy, and Eczema. Immunol Allergy Clin North Am 2011;31:481-91.

36. Pénard-Morand C, Raherison C, Kopferschmitt C, Caillaud D, Lavaud F, Charpin D, et al. Prevalence of food allergy and its relationship to asthma and allergic rhinitis in schoolchildren. Allergy Eur J Allergy Clin Immunol 2005;60:1165-71.

37. Almqvist C, Cnattingius S, Lichtenstein $P$, Lundholm $C$. The impact of birth mode of delivery on childhood asthma and allergic diseases--a sibling study. Clin Exp allergy 2012;42:1369-76.

38. Rizo A. Partos por cesárea: Análisis de los datos de las encuestas nacionales de demografía y salud en Colombia 1995-2005. EAN 2009;67:59-73.

39. Shaheen S, Potts J, Gnatiuc L, Makowska J, Kowalski ML, Joos G, et al. The relation between paracetamol use and asthma: A GA2LEN European case-control study. Eur Respir J 2008;32:1231-6.

40. Beasley R, Clayton T, Crane J, von Mutius E, Lai CKW, Montefort S, et al. Association between paracetamol use in infancy and childhood, and risk of asthma, rhinoconjunctivitis, and eczema in children aged 6-7 years: analysis from Phase Three of the ISAAC programme. Lancet 2008;372:103948.

41. Newson RB, Shaheen SO, Chinn S, Burney PG. Paracetamol sales and atopic disease in children and adults: an ecological analysis. Eur Respir J 2000;16:817-23.

42. Amberbir A, Medhin G, Hanlon C, Britton J, Venn A, Davey G. Frequent use of paracetamol and risk of allergic disease among women in an Ethiopian population. PLoS One 2011;6:e22551.

43. Kelly FJ. Gluthathione: in defence of the lung. Food Chem Toxicol 1999;37:963-6.

44. Nuttall SL, Khan JN, Thorpe GH, Langford N, Kendall MJ. The impact of therapeutic doses of paracetamol on serum total antioxidant capacity. J Clin Pharm Ther 2003;28:289-94.

45. Rahman I, MacNee W. Oxidative stress and regulation of glutathione in lung inflammation. Eur Respir J Off J Eur Soc Clin Respir Physiol 2000;16:534-54.

46. Varner AE, Busse WW, Lemanske RF Hypothesis: decreased use of pediatric aspirin has contributed to the increasing prevalence of childhood asthma. Ann Allergy Asthma Immunol 1998:81:347-51.

47. Galindo P, Borja J, Mur P, Feo F, Gómez E. Anaphylaxis to paracetamol. Allergol Immunopathol (Madr) 1998;26:199-200.

48. Vidal C, Pérez-Carral C, González-Quintela A. Paracetamol (acetaminophen) hypersensitivity. 1997.

49. Lowe a. J, Carlin JB, Bennett CM, Hosking CS, 
Allen KJ, Robertson CF, et al. Paracetamol use in early life and asthma: prospective birth cohort study. Bmj 2010;341:c4616c4616.

50. Holgate ST. The acetaminophen enigma in asthma. Am J Respir Crit Care Med 2011;183:147-8.

51. Rodríguez J, Ruíz F, Peñalosa E, Eslava J, Gómez L, Sánchez H, et al. Encuesta Nacional de Salud 2007. Resultados Nacionales. 1ra ed. Bogotá: Fundación Cultura Javeriana de Artes Gráficas JAVEGRAF-; 2009.

\section{Dr. Augusto Peñaranda}

Department of Otorrinolaringology

Fundación Santa Fe de Bogotá

Bogotá

Colombia

Carrera 9 No. 116-20,

Office 205 Fundación Santa Fe de

Bogotá

Colombia

Tel: + 57-1-2152713/

$+57-1-2152710$

E-mail: augpenar@gmail.com 